\title{
Have Any Changes in Pain Been Noted After a Hemorrhoidectomy Since the Establishment of the Milligan-Morgan Hemorrhoidectomy?
}

\author{
Do Sun Kim \\ Department of Surgery, Daehang Hospital, Seoul, Korea
}

See Article on Page 111-116

Postoperative pain is the major drawback of a hemorrhoidectomy. Researchers have sought solutions to this problem by looking at surgical techniques, topical medications, and surgical devices. First, surgical techniques have drawn attention since the basic techniques of a hemorrhoidectomy were established. Which technique is ideal or more suitable for a hemorrhoidectomy has long been a subject of debate. Because of enthusiasm to find an ideal technique, numerous techniques have been introduced into practice. However, no solid evidence exists for one technique having an absolute advantage over other techniques in terms of postoperative pain [1]. Thus, one can draw the conclusion that no drastic change in terms of pain after a hemorrhoidectomy can be achieved only by modifying or changing the surgical technique. Another attempt to alleviate pain after a hemorrhoidectomy has been attempts to find topical agents that might facilitate wound healing and alleviate pain by decreasing the internal sphincter tone [2]. Although sporadic reports of improved results have been published, most topical agents are regarded as supplementary measures that provide little improvement in pain management. With the development of energy devices for use in a wide variety of surgeries, studies have been conducted to confirm that these devices can, indeed, reduce pain after a hemorrhoidectomy $[3,4]$. These devices are presumed to have an advantage in terms of pain because their use seems to result in less thermal damage. Despite several reports suggesting that the new energy devices may cause

Correspondence to: Do Sun Kim, M.D.

Department of Surgery, Daehang Hospital, 2151 Nambusunhwan-ro, Seocho-gu, Seoul 06699, Korea

Tel: +82-2-6388-8114, Fax: +82-2-6388-8673

E-mail: dskim1@daehang.com

(C) 2016 The Korean Society of Coloproctology

This is an open-access article distributed under the terms of the Creative Commons Attribution NonCommercial License (http://creativecommons.org/licenses/by-nc/4.0) which permits unrestricted noncommercial use, distribution, and reproduction in any medium, provided the original work is properly cited. less pain after a hemorrhoidectomy, the advantage is thought not to be sufficient to bring about a fundamental change in the surgical practice for treating hemorrhoids.

Although many attempts have been made to deal with pain after a hemorrhoidectomy, none, except the stapled hemorrhoidopexy, seems to have been successful. The stapled hemorrhoidopexy is a completely different approach from a hemorrhoidectomy [5]. Because it is performed in a less pain-sensitive region, it seems, apart from an increased risk of recurrence, to have an advantage over a conventional hemorrhoidectomy in terms of postoperative pain. However, from a technical point of view, that surgical approach is not a hemorrhoidectomy, but rather a hemorrhoidopexy. Therefore, one may conclude that no significant reductions in pain after a hemorrhoidectomy have been achieved as of yet, even though changes in and modifications of the surgical technique, as well as the introduction and use of new surgical devices, may bring about some changes in the postoperative outcomes of a hemorrhoidectomy.

\section{CONFLICT OF INTEREST}

No potential conflict of interest relevant to this article was reported.

\section{REFERENCES}

1. Kim DS. Open hemorrhoidectomy. J Korean Soc Coloproctol 2007;23:279-85.

2. Hwang DY, Yoon SG, Kim HS, Lee JK, Kim KY. Effect of 0.2 percent glyceryl trinitrate ointment on wound healing after a hemorrhoidectomy: results of a randomized, prospective, double-blind, placebo-controlled trial. Dis Colon Rectum 2003;46:950-4.

3. Tan EK, Cornish J, Darzi AW, Papagrigoriadis S, Tekkis PP. Metaanalysis of short-term outcomes of randomized controlled trials of LigaSure vs conventional hemorrhoidectomy. Arch Surg 2007; 142:1209-18.

4. Lim DR, Cho DH, Lee JH, Moon JH. Comparison of a hemor- 
rhoidectomy with ultrasonic scalpel versus a conventional hemorrhoidectomy. Ann Coloproctol 2016;32:111-6.

5. Senagore AJ, Singer M, Abcarian H, Fleshman J, Corman M, Wexner S, et al. A prospective, randomized, controlled multi- center trial comparing stapled hemorrhoidopexy and Ferguson hemorrhoidectomy: perioperative and one-year results. Dis Colon Rectum 2004;47:1824-36. 